\title{
Gated SPECT MPI and CT venography fusion: A new approach for appropriate CRT-pacemaker lead placement?
}

\author{
D. O. Verschure, $M D, P h D,{ }^{a, b}$ and H. J. Verberne, $M D, P h D^{a}$ \\ a Department of Radiology and Nuclear Medicine, F2-238, Amsterdam UMC, Location AMC, \\ University of Amsterdam, Amsterdam, The Netherlands \\ b Department of Cardiology, Zaans Medical Center, Zaandam, The Netherlands
}

Received Aug 22, 2019; accepted Aug 22, 2019

doi:10.1007/s12350-019-01882-x

\section{See related article, pp. 1438-1445}

Cardiac resynchronization therapy (CRT) is a disease-modifying therapy and has been shown to improve left ventricular ejection fraction (LVEF), reduce heart failure (HF) related hospitalization and decrease allcause mortality in selected HF patients. ${ }^{1,2}$ CRT is currently recommended as a class IA indication in symptomatic HF patients with LVEF is $\leq 35 \%$, sinus rhythm and a QRS duration $\geq 150 \mathrm{~ms}^{3}$ However, onequarter to one-half of the subjects who receive a CRT are "non-responders" and do not benefit from CRT device implantation. ${ }^{4,5}$ Suboptimal pacemaker lead positioning is one of the multifactorial factors associated with non-response to CRT. ${ }^{6}$ In general, pacing the posterolateral $\mathrm{LV}$ results in the best haemodynamic response. ${ }^{7}$ However, scar in the paced region seems to be associated with poor response to CRT. ${ }^{8}$ Speckletracking echocardiography and late gadolinium enhancement (LGE) cardiac magnetic resonance (CMR) have shown that LV CRT-pacemaker lead placement in viable segments with the latest mechanical activation is associated with acute haemodynamic response and better outcome. ${ }^{9-12}$ Shetty et al. showed that it is feasible to acquire, overlay, and accurately register CMR-derived anatomical, scar, and dyssynchrony data to guide CRT device implantation. ${ }^{11}$ Unlike CMR, gated SPECT

Reprint requests: D. O. Verschure, MD, PhD, Department of Radiology and Nuclear Medicine, F2-238, Amsterdam UMC, Location AMC, University of Amsterdam, Meibergdreef 9, 1105 AZ Amsterdam, The Netherlands; d.o.verschure@amc.uva.nl

J Nucl Cardiol 2021;28:1446-8.

1071-3581/\$34.00

Copyright (C) 2019 American Society of Nuclear Cardiology. myocardial perfusing imaging (MPI) is widely available at relatively low costs. Therefore, gated SPECT MPI has been evaluated for optimal LV CRT-pacemaker lead positioning. ${ }^{13,14}$ Recently, Zhang et al. demonstrated in 79 patients that CRT response improved when LV CRTpacemaker lead position was based on gated SPECT MPI [response was defined as a reduction of $\geq 15 \%$ in LV end-systolic volume (LVESV)]. ${ }^{15}$ After excluding 11 patients with LV CRT-pacemaker pacemaker lead placement in apical of scarred segments, $75.6 \%$ of the patients with LV CRT-pacemaker lead position based on gated SPECT MPI $(n=41)$ responded to CRT while only $51.9 \%$ of patients where LV CRT-pacemaker lead position was not based on gated SPECT MPI $(n=27)$ showed CRT response $(P=0.043)$. Furthermore pacing in the recommended LV segments, identified using gated SPECT MPI, was associated with long-term prognosis. Over a median follow-up of 49 months, 4 patients died $(9.8 \%)$ in the recommended group, 7 $(25.9 \%)$ in the non-recommended group, and $5(45.5 \%)$ in patients where the LV CRT-pacemaker lead was positioned in the apex or scar. There were $9(22.0 \%)$ composite events (all-cause mortality or HF hospitalization) in the recommended group, $14(51.9 \%)$ in the non-recommended group, and $7(63.6 \%)$ in the apex or scar group.

Although identifying the optimal LV CRT-pacemaker lead position by excluding scar tissue is key, the optimal LV CRT-pacemaker lead position is not always feasible due to variations in coronary sinus (CS) anatomy. Cardiac CT has been shown to have additional value for non-invasive visualizing myocardial anatomy, including the CS anatomy. Combining viability and known CS anatomy can result in optimal LV CRTpacemaker lead placement, reducing fluoroscopy time, reducing procedure time, and last but not least reducing peri-procedural complications. In this issue of the 
Journal of Nuclear Cardiology Tada et al. evaluated in a proof-of-principle study the feasibility of a novel approach, named the FIVE STaR method (Fusion Image using CT Venography and perfusion SPECT applied for cardiac Resynchronization therapy), to optimize the efficacy of CRT device implantation. ${ }^{16}$ Four patients referred for CRT device implantation underwent rest SPECT MPI and CT venography prior to CRT implantation. The authors chose as definition of CRT response $\geq 15 \%$ decrease of $\mathrm{LVESV}, \geq 5 \%$ increase of $\mathrm{LVEF}$ and decrease of at least one NYHA class at follow-up (3 months or later after CRT implantation). All patients ( $n$ $=4$ ) that were evaluated using the FIVE STaR method showed CRT response according to all the different criteria used by the authors. In addition, there were no peri-procedural complications. Although a comparison with standard procedures is missing, not allowing for comparison in overall procedure time, fluoroscopy time and complications, this new method seems feasible.

Despite it has been 2 decades after the introduction of CRT into the clinical arena a consensus on how to define CRT response is still lacking. Clinical trials and registries used a variety of different outcome measures without a unified composite endpoint. ${ }^{17}$ Early studies used parameters reflecting functional improvement (6minutes walk test and NYHA functional class). ${ }^{18,19}$ More recent CRT trials used $\mathrm{HF}$ hospitalization and death as a more objective, hard clinical endpoints. ${ }^{1,2}$ Besides clinical events and mortality, surrogate outcomes such as LV remodeling measures (i.e. improvement of LVEF, LVESV, and end-diastolic volume (LVEDV)) were also used in clinical trials. Consequently, different means of measuring response to CRT yield dissimilar response rates as they examine different aspects and severity of HF, in different populations, over different periods of time. This hampers comparison between different studies and will limit in obtaining the real clinical value of CRT.

Tada et al. chose $a \geq 5 \%$ increase of LVEF measured by echocardiography. However, this cut-off value lies within the inter- and intra-operator variability of LVEF measurement by echocardiography. ${ }^{20}$ Therefore, it is advisable to choose another cut-off value of LVEF. Furthermore, using a decrease in NYHA class as an endpoint is limited by subjectivity in assessing NYHA classification. As the FIVE STaR method by Tada et al. seem to be promising, it should be evaluated in larger cohorts of patients referred for CRT. However, as long as there is no consensus on how to best define CRT response, it is advisable to limit to hard clinical endpoints and more objective endpoints with limited interand intra-operator variability and excellent reproducibility such as LV remodeling measures as assessed with gated SPECT MPI.

\section{Disclosure}

Derk O. Verschure and Hein J. Verberne have no conflict of interest to declare.

\section{References}

1. Cleland JGF, Daubert J-C, Erdmann E, Freemantle N, Gras D, Kappenberger L, et al. The effect of cardiac resynchronization on morbidity and mortality in heart failure. New Engl $\mathrm{J}$ Med 2005;352:1539-49.

2. Bristow MR, Saxon LA, Boehmer J, Krueger S, Kass DA, De Marco T, et al. Cardiac-Resynchronization therapy with or without an implantable defibrillator in advanced chronic heart failure. New Engl J Med 2004;350:2140-50.

3. Ponikowski P, Voors AA, Anker SD, Bueno H, Cleland JG, Coats AJ, et al. ESC Guidelines for the diagnosis and treatment of acute and chronic heart failure: The Task Force for the diagnosis and treatment of acute and chronic heart failure of the European Society of Cardiology (ESC). Developed with the special contribution of the Heart Failure Association (HFA) of the ESC. Eur J Heart Fail 2016;18:891-975.

4. Fornwalt BK, Sprague WW, BeDell P, Suever JD, Gerritse B, Merlino JD, et al. Agreement is poor among current criteria used to define response to cardiac resynchronization therapy. Circulation 2010;121:1985-91.

5. Auricchio A, Prinzen FW. Non-responders to cardiac resynchronization therapy: The magnitude of the problem and the issues. Circ J 2011;75:521-7.

6. Bleeker GB, Kaandorp TA, Lamb HJ, Boersma E, Steendijk P, de Roos A, et al. Effect of posterolateral scar tissue on clinical and echocardiographic improvement after cardiac resynchronization therapy. Circulation 2006;113:969-76.

7. Dekker AL, Phelps B, Dijkman B, van der Nagel T, van der Veen FH, Geskes GG, et al. Epicardial left ventricular lead placement for cardiac resynchronization therapy: Optimal pace site selection with pressure-volume loops. J Thorac Cardiovasc Surg 2004; $127: 1641-7$

8. Delgado V, van Bommel RJ, Bertini M, Borleffs CJ, Marsan NA, Arnold CT, et al. Relative merits of left ventricular dyssynchrony, left ventricular lead position, and myocardial scar to predict longterm survival of ischemic heart failure patients undergoing cardiac resynchronization therapy. Circulation 2011;123:70-8.

9. Duckett SG, Ginks MR, Knowles BR, Ma Y, Shetty A, Bostock J, et al. Advanced image fusion to overlay coronary sinus anatomy with real-time fluoroscopy to facilitate left ventricular lead implantation in CRT. Pacing Cin Electrophysiol 2011;34:226-34.

10. Khidir MJH, Abou R, Yilmaz D, Ajmone Marsan N, Delgado V, Bax JJ. Prognostic value of global longitudinal strain in heart failure patients treated with cardiac resynchronization therapy. Heart Rhythm 2018;15:1533-9.

11. Shetty AK, Duckett SG, Ginks MR, Ma Y, Sohal M, Bostock J, et al. Cardiac magnetic resonance-derived anatomy, scar, and dyssynchrony fused with fluoroscopy to guide LV lead placement in cardiac resynchronization therapy: A comparison with acute haemodynamic measures and echocardiographic reverse remodelling. Eur Heart J Cardiovasc Imaging 2013;14:692-9.

12. Marsan NA, Westenberg JJ, Ypenburg C, van Bommel RJ, Roes S, Delgado $\mathrm{V}$, et al. Magnetic resonance imaging and response to cardiac resynchronization therapy: Relative merits of left ventricular dyssynchrony and scar tissue. Eur Heart J 2009;30:2360-7. 
13. Friehling M, Chen J, Saba S, Bazaz R, Schwartzman D, Adelstein $\mathrm{EC}$, et al. A prospective pilot study to evaluate the relationship between acute change in left ventricular synchrony after cardiac resynchronization therapy and patient outcome using a single-injection gated SPECT protocol. Circ Cardiovasc Imaging 2011;4:532-9.

14. Boogers MJ, Chen J, van Bommel RJ, Borleffs CJ, Dibbets-Schneider P, van der Hiel B, et al. Optimal left ventricular lead position assessed with phase analysis on gated myocardial perfusion SPECT. Eur J Nuc Med Mol Imaging 2011;38:230-8.

15. Zhang X, Qian Z, Tang H, Hua W, Su Y, Xu G, et al. A new method to recommend left ventricular lead positions for improved CRT volumetric response and long-term prognosis. J Nuc Cardiol 2019. https://doi.org/10.1007/s12350-019-01735-7.

16. Tada T, Osuda K, Nakata T, Muranaka I, Himeno M, Muratsubaki $\mathrm{S}$, et al. A novel approach to the selection of an appropriate pacing position for optimal cardiac resynchronization therapy using CT coronary venography and myocardial perfusion imaging: FIVE STaR method (fusion image using CT coronary venography and perfusion SPECT applied for cardiac resynchronization therapy). J Nucl Cardiol 2019. https://doi.org/10.1007/s12350-019-01856-z.
17. Daubert C, Behar N, Martins RP, Mabo P, Leclercq C. Avoiding non-responders to cardiac resynchronization therapy: A practical guide. Eur Heart J 2017;38:1463-72.

18. Uszko-Lencer N, Mesquita R, Janssen E, Werter C, Brunner-La Rocca HP, Pitta F, et al. Reliability, construct validity and determinants of 6-minute walk test performance in patients with chronic heart failure. Int J Cardiol 2017;240:285-90.

19. Bennett JA, Riegel B, Bittner V, Nichols J. Validity and reliability of the NYHA classes for measuring research outcomes in patients with cardiac disease. Heart Lung 2002;31:262-70.

20. Cole GD, Dhutia NM, Shun-Shin MJ, Willson K, Harrison J, Raphael CE, et al. Defining the real-world reproducibility of visual grading of left ventricular function and visual estimation of left ventricular ejection fraction: Impact of image quality, experience and accreditation. Int J Cardiovasc Imaging 2015;31:1303-14.

Publisher's Note Springer Nature remains neutral with regard to jurisdictional claims in published maps and institutional affiliations. 